\title{
CARNAVAL DE URUGUAIANA O SAMBA DA FRONTEIRA PEDE PASSAGEM!
}

Fábio Pavão (UFF)

Desde a década de 1930 o samba e, consequentemente, as escolas de samba do Rio de Janeiro se tornaram referência para o surgimento e a organização de manifestações culturais semelhantes em várias partes do Brasil. Este artigo procura mostrar o simbolismo do espetáculo das escolas de samba na cidade de Uruguaiana, na fronteira oeste do Rio Grande do Sul, especialmente em suas interações com a cultura tradicionalista e as singularidades do carnaval em região fronteiriça.

REGIONALISMO, TRADICIONALISMO, IDENTIDADE, CARNAVAL.

PAVÃO, Fábio. Carnaval de Uruguaiana: o samba da fronteira pede passagem! Textos escolhidos de cultura e arte populares, Rio de Janeiro, v.8, n.2, p. 101114, nov. 2011. 


\section{ENTRE O CAMPO E O DEVER}

Uruguaiana está localizada na fronteira oeste do Rio Grande do Sul, a 649 quilômetros de Porto Alegre. Desde 2007, o corpo de jurados do carnaval da cidade é proveniente do Rio de Janeiro. Coube à prefeitura municipal, juntamente com o jornalista gaúcho Cláudio Brito, principal responsável pela cobertura carnavalesca na cidade e na capital gaúcha, convidar pessoas que não estavam inseridas no contexto do carnaval local para integrar o grupo de julgadores, tendo em vista as muitas confusões envolvendo o resultado do julgamento nos anos anteriores. A partir de então, um grupo formado por sambistas, jornalistas e pesquisadores do carnaval carioca é anualmente selecionado para avaliar o trabalho apresentado pelas agremiações locais.

Nas vésperas do carnaval de 2009, fui convidado para integrar o corpo de jurados, substituindo, no quesito enredo, o famoso carnavalesco Renato Lage, que havia comunicado a impossibilidade de seguir para Uruguaiana. Naquela oportunidade, estava escrevendo minha tese de doutorado, que seria defendida no início do ano seguinte, e que buscava compreender como o samba, que ao longo do século XX se consolidara como um símbolo nacional homogeneizador, a partir de uma série de fatores que favoreciam o papel centralizador do Rio de Janeiro, então capital da República, era apropriado e usado pelos atores sociais de acordo com o contexto das interações, especialmente naquilo que costumamos definir como globalização e seus choques entre o global e o local. Em determinada parte, discutia, a partir da relação entre o samba e as práticas regionais, as tensões e conflitos entre o nacional e regional, analisando dados empíricos e depoimentos de sambistas de outros estados do Brasil, como São Paulo.

Estar em Uruguaiana, portanto, se apresentava como oportunidade única para observar como esse encontro entre o nacional e o regional acontecia em uma cidade do Rio Grande do Sul, estado em que o tradicionalismo transformava a cultural local em importante sinal diacrítico. Estava ciente das tensões entre as escolas de samba e a tradicional cultura gaúcha em Porto Alegre, porém, em Uruguaiana, tal encontro entre o regional e o nacional acontecia em cenário bastante peculiar. Uruguaiana é cidade de fronteira, localizada às margens do Rio Uruguai, que separa os territórios de Brasil e Argentina. Nessa condição, aquele carnaval seria especial, pois, além dos aspectos nacionais e regionais, seria possível perceber as influências transnacionais típicas de qualquer região fronteiriça.

A condição de jurado, contudo, erguia barreiras e estabelecia limites para as observações acadêmicas. Não faria, pois, um trabalho de campo sistemático, como realizava no Rio de Janeiro. Apenas conheceria pessoalmente o carnaval de Uruguaiana e, aproveitando a oportunidade, estaria em contato com sambistas e jornalistas que vivem o espetáculo, obtendo informações importantes. Como esse não era o foco central da tese, minha intenção era apenas fazer menção a uma realidade sui generis. O pulsar das ruas de Uruguaiana, todavia, mostrou-se bastante revelador, enriquecendo a qualidade dos dados e informações que eu conseguia. Novas perguntas surgiram e, nos anos seguintes, 
com a tese já concluída e defendida, os retornos à cidade possibilitaram ampliar a compreensão do simbolismo daquele carnaval na fronteira.

Este artigo procura expandir as análises realizadas para a tese, incluindo dados que não foram aproveitados na oportunidade, pois fugiam da proposta do trabalho, e outras observações realizadas ao longo de meus dois retornos ao carnaval de Uruguaiana. Todavia, tal experiência não pode ser inserida naquilo que nós, antropólogos, costumamos chamar de "trabalho de campo". Os dados empíricos aqui apresentados fazem parte de análise preliminar. Uma análise que não pretende ser conclusiva, mas apenas lançar uma luz sobre um espetáculo pouco conhecido no Brasil e, consequentemente, que passa ao largo dos estudos acadêmicos.

\section{O SAMBA COMO ELEMENTO NACIONAL}

Pelo menos desde a década de 1950, o carnaval da cidade gaúcha de Uruguaiana tem como principal atração o desfile das escolas de samba, seguindo o modelo de organização e os elementos rituais consagrados no Rio de Janeiro. Nesse aspecto, Uruguaiana, assim como muitos outros municípios do país, seguiu a tendência de incorporar elementos que, simbolicamente, conseguiam relativa hegemonia no campo das representações sobre a nação, destacando-se como "elemento nacional", ou seja, homogeneizador, diante da diversidade regional que caracteriza nosso país. Antes de entrarmos especificamente nas análises dessa festa, é necessário fundamentar teoricamente esta última afirmação, facilitando a compreensão daquilo que definimos por elementos "nacionais" e "regionais".

A partir da década de 1930, o samba, bem como, consequentemente, a imagem do sambista, se consolidou como uma das principais representações do Brasil e do povo brasileiro, ascendendo à condição de símbolo de identidade nacional, acima das demais práticas locais ou regionais. Ao fazer essa afirmação, temos como principal referência a tese de Hermano Vianna (1995), que transforma essa questão em um dos pontos centrais de seu "mistério do samba". Segundo esse autor, um novo modelo de autenticidade do Brasil foi fabricado a partir do Governo Vargas, tendo como base o amplo debate de nossos intelectuais sobre a mestiçagem. Nesse processo, o samba, expressão da cultura popular urbana do Rio de Janeiro, então capital federal, teria alcançado a posição de música nacional e colocado em condição secundária outros gêneros musicais, contando, para esse feito, com o apoio governamental federal, desde o morro até a exposição nacional (VIANNA, 2007, p. 61 e 126).

Seguramente, o projeto político centralizador de Vargas, assim como a mediação cultural exercida por alguns importantes intelectuais, outro aspecto destacado pelo autor, foi fundamental nesse processo. Acrescentamos, todavia, outros fatores, presentes no Rio de Janeiro da década de 1930, que possibilitaram a difusão do samba para o restante do território nacional e sua coexistência com as práticas culturais regionais, facilitando a compreensão de algumas análises que faremos adiante. 
Em primeiro lugar, a incorporação de elementos da cultura popular como símbolos nacionais não chega a constituir novidade, sendo comum, por exemplo, na formação do imaginário nacional de várias nações europeias. Nesse processo, os elementos da cultura popular deixam a condição social periférica para se tornar simbolicamente centrais, mas, para isso, é necessário que haja o esvaziamento de seus antigos conteúdos políticos reivindicatórios ou étnicos, que assumem a condição de elementos comuns e extensivos a todos os demais grupos sociais a quem devem representar. O samba carioca, produção cultural de uma recém-descoberta classe urbana de origem negra, trazia em sua essência matriz africana e reelaboração de hábitos, costumes e expressões culturais de outras classes e grupos sociais.

Na década de 1930, uma nova ideologia acerca das relações raciais torna-se hegemônica, tendo como base a noção de "democracia racial", tal qual é concebida por Gilberto Freyre. Naquele momento histórico, o samba carioca, com seu DNA africano "miscigenado" às demais manifestações culturais, parecia representar de forma adequada o "mito das três raças", que remete o imaginário nacional para inevitável encontro entre povos diferentes, mas "predestinados a construírem uma nação". Assim, o samba carioca poderia ser visto não apenas como mais uma prática cultural regional, mas como elemento que remete a um "mito de origem" da nação brasileira. Logo, nas sombras da "cordialidade" da "democracia racial", o samba pôde tornar-se elemento homogeneizador sem questionar ou invalidar as manifestações regionais. Em outras palavras, apesar da multiplicidade de expressões culturais regionais do país, o samba evocava a própria essência da "brasilidade" por todos compartilhada.

Em segundo lugar, ao procurar estabelecer representações hegemônicas no imaginário sobre a nação, o Governo Vargas buscava forjar elementos comuns com os quais indivíduos de histórias e origens diferentes pudessem identificar-se. Nesse contexto, as emissoras de rádio, nas décadas de 1920 e 1930, ocupam o papel que Benedict Anderson (2008) concede ao "capitalismo editorial", que, graças aos romances e jornais, faz com que um número cada vez maior de pessoas pudesse participar de inédita simultaneidade de ações. Na visão de Anderson, o "capitalismo editorial" permitiu a aproximação de intelectuais e povo, promovendo "camaradagem horizontal" entre indivíduos desconhecidos e possibilitando a formação de uma "comunidade imaginada" nos estados nacionais europeus.

No Brasil, cuja população era formada por grande massa iletrada, a chamada "era do rádio", nas décadas de 1920 e 1930, e mais tarde o advento da televisão, nas décadas de 1950 e 1960, podem ser considerados dois momentos importantes na consolidação de projetos nacionalistas, que, incorporados aos meios de comunicação, conseguiram grande abrangência. $O$ samba, dessa forma, impulsionado pelos sambistas que integravam a programação de emissoras como a Rádio Nacional, despontou como elemento fundamental para o estabelecimento dessa simultaneidade de ações. É também graças ao rádio, assim como à indústria fonográfica, não por acaso ambas sediadas principalmente no Rio de Janeiro, que, nesse período, alguns cantores conquistaram fama além 
das fronteiras nacionais, difundindo o samba no exterior como representante principal do que seria a "legítima música brasileira" (PAVÃo, 2010, p. 311).

Como exemplo dessa ascensão do samba, podemos citar a incorporação desse gênero musical pela indústria cultural norte-americana, o que se reflete nas características do personagem de desenho animado Zé Carioca, um papagaio sambista que surge das pranchetas de Walt Disney como parte da política de boa vizinhança norte-americana, como mostrou Fernandes (2001), e o estrondoso sucesso dos trejeitos de Carmem Miranda em Hollywood. Dessa forma, os estereótipos do sambista passaram a representar a imagem do próprio brasileiro no exterior, contribuindo, também internamente, para o reconhecimento do samba como elemento homogeneizador, independentemente da multiplicidade de expressões regionais presentes ao longo da extensão do vasto território brasileiro.

Na visão de George Yudice (2006, p. 161), o samba se consolidou ao longo dos anos como exemplo de "prática cultural do consenso", isto é, elemento fundamental para a representação de identidade cultural do povo brasileiro, especialmente das classes populares, ao lado de outras manifestações culturais, como o pagode, a capoeira, o candomblé e a umbanda. Esses elementos teriam paulatinamente sido mobilizados por setores importantes da mídia, negócio, turismo, política e outros fatores de mediação para a reprodução simbólica de um Brasil "cordial", que resultou quase sempre em benefícios materiais por parte da elite. Ao afirmar a existência de "prática cultural do consenso", é importante ressaltar, Yudice não está reduzindo as diferenças ou desprezando a diversidade cultural, apenas destacando que, ao longo dos anos, certas práticas adquiriram relativa hegemonia no campo das representações, constituindo poderosos estereótipos. Essa concepção não ignora, entretanto, a realidade empírica que demonstra a existência de outros ritmos e gêneros musicais mais populares e atrativos, sobretudo para as novas gerações, assim como as tensões e conflitos que podem surgir diante da diversidade regional do país.

Assim, o chamado "samba do morro", próprio das classes populares do Rio de Janeiro, passa a fazer sucesso, juntamente com outros tipos de samba, de norte a sul do país. A partir da produção cultural das escolas de samba cariocas, além de um gênero musical, o ritual de desfile incorporará prática cultural rica em expressões performáticas, ampliando a identidade rítmica para um conjunto de manifestações visuais e valores performativos incorporados à imagem de seus adeptos. Os sambistas, em suma, além de comporem ou cantarem sambas, também dominam os passos da dança, rodam com suas saias fartas ou portam a bandeira do grupo, produzem o ritmo tocando instrumentos ou exercem alguma das inúmeras atividades de uma agremiação carnavalesca.

Ao longo do século XX, a partir dos já destacados meios de comunicação e graças à centralidade cultural da antiga capital federal, diversos estados brasileiros, incorporaram não apenas o samba carioca a seus repertórios musicais, mas também fizeram brotar em todo o território nacional escolas de samba, seguindo a estrutura e a organização consolidada no Rio de Janeiro, enriquecendo as festas carnavalescas. Em alguns casos, 
como Olga Von Simson (2007, p. 331) demonstra em São Paulo, os cordões, manifestações culturais já existentes, foram adequando seus rituais carnavalescos às características das escolas de samba cariocas, incorporando elementos até então estranhos aos desfiles paulistanos, como a ala de baianas. Além de grande espaço na mídia, as agremiações carnavalescas do Rio de Janeiro chamavam a atenção por conseguir, nas negociações com o poder público, importantes vantagens que culminaram, ainda nas décadas de 1960 e 1970 , no progressivo interesse de outras classes sociais, notadamente da classe média, e na incorporação do espetáculo aos roteiros turísticos. Copiar o modelo adotado pelas escolas de samba cariocas, dessa forma, parecia a estratégia ideal para conseguir o reconhecimento da população, da imprensa e dos governantes.

Na década de 1980, as escolas de samba do Rio de Janeiro continuavam servindo de referência para as manifestações similares que surgiram pelo Brasil. Em 1984, a construção de espaço definitivo para os desfiles, popularmente chamado de sambódromo, não apenas aumentava a visibilidade das apresentações carnavalescas, como também demonstrava o reconhecimento pelo poder público da importância cultural das escolas de samba. No mesmo ano, surge a Liga Independente das Escolas de Samba - Liesa, comandada pela cúpula do jogo do bicho da região metropolitana do Rio de Janeiro, evidenciando que os sambistas, ou suas lideranças, eram capazes de organizar diretamente seus espetáculos, tendo o poder público apenas como parceiro.

Nos anos seguintes, sambistas de todo o Brasil passaram a organizar suas próprias ligas para gerir seus desfiles, reivindicando a construção de sambódromos semeIhantes ao carioca. Em algumas cidades, como São Paulo, Manaus e Porto Alegre, os espaços definitivos para as apresentações das escolas de samba foram construídos, muitas vezes gerando conflitos com setores da sociedade contrários ao investimento. Além da grande parcela da população que não compreende a necessidade de se investir numa festa como o carnaval, houve, em determinados locais, a oposição de grupos tradicionalistas responsáveis pela valorização das manifestações regionais, como começaremos a ver a seguir, tratando especificamente do Estado do Rio Grande do Sul e da cidade de Uruguaiana.

\section{O CARNAVAL DE URUGUAIANA}

No Rio Grande do Sul, a imagem do gaúcho altivo cavalgando nos pampas, valente e disposto a pelear por sua terra, serviu de modelo para um estereótipo regional reconhecido em todo o país. No entanto, no período carnavalesco, as escolas de samba são a atração principal em grande parte de seus municípios. É o caso, como já dissemos, de Uruguaiana, localizada nas margens do Rio Uruguai, que serve de fronteira natural para Brasil e Argentina. Segundo dados do IBGE, o município, que tem origem na Revolução Farroupilha e serviu de palco para algumas das principais bata-

1. Dados referentes às primeiras informações disponibilizadas pelo censo de 2010.
Ihas travadas durante a Guerra do Paraguai, possui 125.507 habitantes ${ }^{1}$ distribuídos em seu vasto território, o segundo maior do estado gaúcho. Seu principal cartão-postal é a ponte internacio- 
nal que faz a ligação entre o Centro da cidade e Paso de los Libres, esta última localizada na outra margem do rio, em território argentino.

Especialmente para um carioca, as largas e bem planejadas ruas de Uruguaiana em nada lembram Madureira, Vila Isabel, Estácio, Mangueira ou qualquer outro dos muitos bairros ou comunidades reconhecidos como redutos de samba. Entretanto, nos dias de desfiles das escolas de samba, a cidade é tomada por uma mistura de euforia e ansiedade que impressiona os visitantes, mesmo aqueles acostumados com as disputas carnavalescas nas grandes metrópoles. Como é comum nos períodos rituais, o desfile anualmente mobiliza a atenção de todos os habitantes, mudando completamente a rotina. Ele monopoliza as conversas nas esquinas e nos bares da cidade. As rádios locais exploram exaustivamente o assunto, tecendo análises e acirrando os ânimos. Os uruguaianenses, em suma, vestem as cores e os símbolos de suas escolas de coração e encenam os vários papéis que compõe o ritual dos desfiles na cidade, cantando, sambando, torcendo, tratando o adversário de forma jocosa ou, simplesmente, defendendo sua escola em acalorada discussão na mesa de um bar. A proximidade entre Uruguaiana e Rio de Janeiro, contudo, vai muito além da paixão por suas agremiações carnavalescas.

Segundo o jornalista e compositor Francisco Alves (2009), a distância de Uruguaiana para os grandes centros nacionais, incluindo a capital do próprio estado gaúcho, fez com que, até meados do século XX, a influência da cultura argentina na cidade fosse bastante intensa. Enquanto os sinais das rádios do eixo Rio-São Paulo eram de difícil captação, os programas das emissoras uruguaias e, sobretudo, argentinas eram ouvidos por todos os habitantes da região. Os lançamentos de tangos e outras novidades que vinham da margem oposta do Rio Uruguai eram imediatamente difundidos pela cidade, enquanto o que ocorria no Rio de Janeiro e, como vimos, estava fazendo sucesso no restante do território nacional demorava a chegar ao estúdio da Rádio Charrua, principal emissora local.

Enquanto a cidade permanecia isolada do restante do país, as tradicionais murgas, até hoje comuns no Uruguai e em algumas regiões da Argentina, basicamente composta por um conjunto de músicos com pandeiro, violão, bombos, legueros, tumbadoras e instrumentos de sopro, faziam parte também da cultura uruguaianense. Os primeiros blocos locais surgiram ainda nesse período de isolamento, mas foi na década de 1950, a partir da chegada de um grande contingente de fuzileiros navais vindos de várias partes do Brasil, mas sediados em quartéis do Rio de Janeiro, que o samba e o carnaval de Uruguaiana teriam adquirido algumas das características que os distinguem de quaisquer outros no estado.

Em seus momentos de lazer, ainda segundo Francisco Alves (2009), os soldados se reuniriam fardados para cantar sambas carnavalescos e dos morros cariocas, de forma que não teriam demorado a se integrar aos moradores e participar dos festejos da cidade, criando a Escola de Samba Filhos do Mar, que trouxe importantes transformações para o carnaval na fronteira oeste gaúcha. Muitos desses militares acabaram se estabelecendo definitivamente em Uruguaiana, passando a fazer parte das agremiações carna- 
valescas locais que em pouco tempo passaram a "batucar o samba novo", aproximando seus ritmos ao que era praticado no Rio de Janeiro.

Nas disputas carnavalescas do município, a Escola de Samba Filhos do Mar conquistou três títulos de campeã, sendo o último em 1961. Todavia, mesmo depois de extinta, seu legado permanece no modelo carioca de brincar carnaval, mesclado às nuanças da cultura gaúcha, que as agremiações carnavalescas da cidade mantêm até os dias de hoje. Das várias escolas que surgiram nas décadas de 1950 e 1960, quando o atual modelo de desfiles se consolidou em Uruguaiana, apenas a Os Rouxinóis, fundada em 1953, um ano após a Filhos do Mar, continua em atividade. As demais escolas de samba que em 2011 participaram do principal desfile da cidade e seus respectivos anos de fundação são: Cova da Onça (1970), Ilha do Marduque (1977), Deu Chucha na Zebra (1979), Bambas da Alegria (2000), Apoteose do Samba (2004), Unidos de São Miguel (1999) e Imperadores do Sol (2007).

Entre 1952 e 2004, o carnaval de Uruguaiana cresceu e se tornou cada vez mais importante no sudoeste rio-grandense, acompanhando e incorporando as novidades que aconteciam no Rio de Janeiro, tanto em relação aos aspectos rituais quanto à organização. Um exemplo disso foi a criação, em 1991, sete anos após a similar carioca, da Liga Independente das Escolas de Samba de Uruguaiana - Liesu, que possibilitou aos próprios sambistas participação mais ativa no planejamento da festa, em parceria com o poder público. Todavia, algumas particularidades no regulamento diferenciam o carnaval da cidade gaúcha do que acontece no Rio de Janeiro ou mesmo em Porto Alegre. Um exemplo é o costume de as escolas de samba desfilarem oficialmente duas vezes, ao longo de três dias reservados para as apresentações, o que causa estranheza aos visitantes dos grandes centros.

No entanto, o que mais chama a atenção no carnaval de Uruguaiana é o fato de os desfiles acontecerem em data posterior ao calendário oficial. Até então, apesar do crescimento e do sucesso alcançado na região, a visibilidade dos grandes centros ofuscava o brilho das escolas uruguaianenses. Além do Rio de Janeiro, cuja influência carnavalesca se estende para todo o território nacional, com o auxílio da principal rede de televisão do país, o desfile de Porto Alegre, capital do estado e cuja influência cultural naturalmente se estendia até a região, gozava de grande visibilidade e admiração. A história do carnaval de Uruguaiana, contudo, começa a mudar em 2004, quando, após a interdição da quadra de ensaios de uma agremiação pelo Ministério Público, fato que atrasou as atividades e impossibilitou o cumprimento do calendário carnavalesco, o adiamento dos desfiles para a primeira semana de março foi a única forma encontrada para que a escola pudesse apresentar-se.

No princípio, a Igreja protestou diante da heresia de se brincar carnaval em período reservado à penitência, entrando em conflito com as escolas, a prefeitura e a Liesu. O desfile na Quaresma parecia ser um problema, mas, na verdade, possibilitou um grande salto de qualidade. A objeção religiosa logo foi solucionada e, com o novo calendário festivo, sambistas de várias partes do Brasil, sobretudo dos grandes centros, que nos dias 
oficiais de carnaval possuem compromissos com suas escolas e em suas cidades, puderam participar e acompanhar o evento. Isso deu grande visibilidade à festa, promovendo importante intercâmbio entre Uruguaiana e as escolas de Porto Alegre, Rio de Janeiro e, em menor escala, São Paulo. A partir de então, profissionais renomados passaram a desfilar nas agremiações locais. Muitas fantasias, esculturas e até alegorias inteiras passaram a vir da capital gaúcha ou do sudeste do país para desfilar no "carnaval fora de época" de Uruguaiana, dando outra dimensão ao espetáculo.

Essa mudança, contudo, não significou o desaparecimento da festa carnavalesca na data oficial. A partir de 2004, sem o desfile das escolas de samba nos dias dedicados a Momo, o carnaval de Uruguaiana praticamente se limitou a realização de bailes nos principais clubes sociais. Pelas ruas, é possível encontrar o jogo de "bexiguinha", nome pelo qual são chamadas as bolas com água que são arremessadas. Em toda a cidade existe apenas um bloco de sujo, que desfila pelas principais ruas do Centro com banda, carro de som e, como é comum na festa carnavalesca de outras partes do Brasil, pessoas fantasiadas e homens vestidos de mulher. Grande parte da população, entretanto, alheia a essas atrações e ávida por aproveitar os dias de feriado, viaja para as praias, localidades próximas ou para o interior do próprio município. Nos dias de desfiles das escolas de samba, contudo, lotam as arquibancadas para acompanhar o que alguns consideram ser o "terceiro maior carnaval do Brasil".

\section{O SAMBA E O TRADICIONALISMO GAÚCHO}

Nos últimos anos, os sambistas de Uruguaiana e a municipalidade local encamparam como marketing o slogan de que a cidade teria o "terceiro maior carnaval do Brasil". No caso, a palavra "carnaval", como é comum entre os sambistas, também no Rio de Janeiro, está sendo empregada como sinônimo de desfile de escola de samba. Assim, segundo essa afirmativa, as agremiações carnavalescas uruguaianenses estariam atrás apenas das similares cariocas e paulistanas, apresentando um espetáculo superior até mesmo ao de Porto Alegre.

Essa assertiva é bastante polêmica e, para os propósitos deste artigo, não valeria a pena comparação entre os desfiles carnavalescos na capital do estado e na região de fronteira. Todavia, é importante ressaltar os diferentes lugares simbólicos que as agremiações carnavalescas hierarquicamente ocupam nas duas cidades, o que nos permite discutir a relação entre os elementos nacionais e regionais dentro do estado gaúcho. 0 movimento tradicionalista, rigoroso na defesa e na preservação de uma "autêntica cultura do Rio Grande do Sul", espalhou não só pelo estado, mas por várias cidades do Brasil, os famosos Centros de Tradições Gaúchas - CTGs, transformando a cultura sulista em sinal diacrítico que distingue o estado do restante do país, ou, visto de outra forma, estabelece distinção entre os aspectos regionais e as práticas culturais que tentam homogeneizar as representações de uma identidade nacional.

No Rio Grande do Sul, a prática e o consumo das expressões regionais gaúchas, oferecida pelos tradicionalistas na maioria das grandes cidades brasileiras, adquire signi- 
ficados simbólicos que remetem à resistência frente à hegemonia da indústria cultural do eixo Rio-São Paulo e à primazia de "práticas consensuais" construídas pelos estereótipos inclusivos que procuram definir a nacionalidade brasileira, como a miscigenação e a "democracia racial". No Sul do país, entre as influências de imigrantes europeus das mais variadas procedências, lendas indígenas e um histórico de contatos e conflitos com os vizinhos de origem hispânica, a herança cultural africana, em relação às demais regiões do Brasil, se não está de todo ausente, ocupa certamente lugar secundário. O discurso da "democracia racial" ou da mestiçagem, assim, parece não ser capaz de gerar o reconhecimento necessário.

Todavia, ao longo do século XX, o samba, ao se espalhar pelo Brasil, penetrou também o Rio Grande Sul e conquistou, sobretudo, as comunidades negras da capital e de várias cidades do interior, mesmo diante da resistência e da oposição dos tradicionalistas. Nesse conflito, ora latente, ora manifesto, entre sambistas e tradicionalistas, estão em jogo o apoio e o reconhecimento do poder público às manifestações culturais. Em Porto Alegre, as tentativas das escolas de samba de aumentar sua influência junto ao poder público encontra, inevitavelmente, a já consolidada tradição cultural sulista como obstáculo.

Na capital gaúcha, a luta pela construção de um sambódromo para as apresentações, depois de se arrastar por alguns anos, foi vencida, com a construção de espaço que deveria receber não apenas os desfiles carnavalescos, mas também os festejos da semana da Revolução Farroupilha. No entanto, se antes os desfiles carnavalescos eram realizados no Centro da cidade, ao lado do Parque Harmonia, onde anualmente é instalado o acampamento farroupilha, o novo espaço para desfiles foi construído no distante bairro de Porto Seco. Os tradicionalistas, todavia, se recusaram a realizar seus festejos longe do Centro e conseguiram impor sua vontade, permanecendo no antigo Parque.

Simbolicamente, temos nesse processo a expulsão do samba para a periferia da vida social de Porto Alegre, enquanto os festejos tradicionalistas ratificaram sua condição central. São raros os sambistas que transitam pelos Centros de Tradições Gaúchas, ou, no sentido contrário, de tradicionalistas que frequentam o "mundo do samba". O distanciamento entre os dois universos gera muitas vezes situações de preconceito, em que as agremiações carnavalescas, bem como seu conjunto de valores, são colocadas em situação de inferioridade e de não reconhecimento de sua importância cultural. Durante as comemorações da Semana Farroupilha, o Movimento Tradicionalista Gaúcho realiza um desfile de carros alegóricos, que, pela experiência já adquirida no carnaval, são criados pelos carnavalescos das principais escolas de samba da cidade. Entretanto, existe ordem expressa para que o material de divulgação e os releases distribuídos para a imprensa não se refiram a eles como "carnavalescos", chamando-os de "artistas plásticos", sob a argumentação de que o desfile da Semana Farroupilha não é o desfile de carnaval para que eles sejam chamados de "carnavalescos".

Assim, nota-se que o talento e o saber especializado dos artistas carnavalescos são reconhecidos, mas, para exercer sua função em outra atividade fora do carnaval, es- 
pecialmente no tocante aos valores tradicionais da cultura gaúcha, é necessário apagar qualquer referência aos festejos de Momo e ao universo cultural das escolas de samba, definindo-os pela genérica e simbolicamente vazia denominação de "artistas plásticos". No Rio de Janeiro, diferentemente, os carnavalescos também são convidados para as mais diversas atividades, como montar cenário e fazer figurino para espetáculos, decoração de festejos e abertura de eventos, mas sempre tendo ressaltado, pela mídia e pelos organizadores, sua condição de "carnavalesco" como forma de provar sua competência e gerar expectativa em relação à qualidade do trabalho. Nos Jogos Pan-americanos do Rio de Janeiro, em 2007, por exemplo, a tradicional festa de abertura teve a execução da parte artística sob a responsabilidade da carnavalesca Rosa Magalhães, então responsável pela idealização do carnaval da Imperatriz Leopoldinense. Os organizadores, durante toda a preparação do espetáculo, deram destaque ao fato de terem convidado um carnavalesco, ressaltando, principalmente, um diferencial que o espetáculo carioca teria em relação aos já apresentados.

A criação de alegorias para a Semana Farroupilha, em Porto Alegre, e a abertura dos XV Jogos Pan-americanos, no Rio de Janeiro, apontam para algumas questões importantes. Primeiro, a visível diferença em relação à valoração do "mundo do samba" nas duas cidades. Em ambos os casos o talento e o saber específico são reconhecidos, mas, enquanto no Rio de Janeiro a denominação de "carnavalesco" é algo que acrescenta ao currículo e corrobora a expectativa de um espetáculo de qualidade, em Porto Alegre ela comunica condição menor e pouco valorizada no cenário cultural local, tornando mais atrativa a denominação genérica de "artista plástico". Em segundo lugar, a participação na Semana Farroupilha, repleta de valores simbólicos de resistência para os gaúchos tradicionalistas, exige que os vestígios culturais que não fazem parte desse universo tradicional sejam apagados. Só dessa forma o carnavalesco, artista cujo talento é reconhecido e notadamente tem condições de contribuir para a beleza dos festejos, pode transitar entre os dois mundos. Na abertura dos jogos pan-americanos, mesmo sendo evento internacional e bem mais abrangente, da mesma maneira que nas peças teatrais cujos cenários levam a assinatura dos carnavalescos cariocas, essa simbologia não está presente, de forma que a denominação não encontra resistência (PAVÃo, 2010 p. 178-180).

Em Uruguaiana, aparentemente a tradicional cultura gaúcha convive com as escolas de samba de forma mais harmoniosa. Essa impressão é corroborada por Vinícius Brito, jornalista importante para a divulgação do samba gaúcho, que transita pelos carnavais de Porto Alegre e Uruguaiana. Sobre a interação entre a tradicional cultura gauchesca e o samba, ele declara:

Lá [em Uruguaiana], diversos grupos de danças gaúchas integram comissões de frente. Cantores viram puxadores, compositores de vanerão ${ }^{2}$ compõem samba-enredo e assim por diante. Creio que, por ser uma cidade de fronteira com a Argentina, exista uma melhor convivência das diferenças. Além disso, por ser uma cidade militar, sempre teve dezenas de fuzileiros navais cariocas integrando e fundando escolas de samba. ${ }^{3}$ 
2. Tipo de música popular no Rio Grande do Sul, considerada típica e valorizada pelos tradicionalistas.

3. Depoimento ao autor em abril de 2009.

4. Segundo o entrevistado, "grupos tchê" são conjuntos que tocam músicas gauchescas tradicionais, mas acrescentando algumas novidades que, para os tradicionalistas, deturpam as verdadeiras tradições do Rio Grande do Sul.

5. Depoimento ao autor em abril de 2009.
No entanto, nem todos concordam com essa afirmação. Outro jornalista, que é também sambista, Gláucio Guterres, por exemplo, discorda, mas destaca que a fusão cultural acaba acontecendo de qualquer forma, apesar de os grupos que comandam os CTGs manterem as objeções. Em sua visão:

$\mathrm{O}$ tradicionalismo é muito reservado e fechado, mas a cultura é superior a tudo isso, pois é impossível obstruir a fusão cultural, já que nenhuma cultura domina eternamente outrem. Acho que o carnaval por ser uma cultura mais aberta até possibilitou aos grupos tradicionalistas apresentarem os movimentos harmônicos produzidos nos salões dos CTGs, mas a recíproca ainda está por acontecer. Eu percebo que os tradicionalistas visualizam como invasão de espaço, prova que os CTGs não aceitam nem os grupos "Tchê!"4, ou seja, acreditam ser válida somente a música gaúcha tradicional. ${ }^{5}$

Em ambos os depoimentos, a fusão cultural, isto é, uma mistura de elementos do samba com a tradição cultural gaú-

cha, é citada. Isso não é singularidade de Uruguaiana nem do Rio Grande do Sul. Em todas as regiões que formaram escolas de samba seguindo o modelo carioca, as características importadas da manifestação cultural se mesclaram inevitavelmente aos valores locais. De fato, em um mundo cada vez mais globalizado, o samba, com seus seguidores e praticantes em várias partes do Brasil e do mundo, é uma expressão cultural híbrida e caracterizada pelos contatos culturais. O que merece destaque é o fato de que, apesar da oposição dos tradicionalistas e dos usos e do consumo da cultura gauchesca como resistência aos aspectos homogeneizadores, da qual o samba é excelente exemplo, é impossível, especialmente na cidade da fronteira gaúcha, erguer barreiras capazes de manter práticas culturais puras e livres de influências.

Por ser cidade de fronteira, além de estar acostumada com as diferenças, como destacou Vinicius Brito, Uruguaiana convive com aspectos híbridos que estão além do debate entre o nacional e o regional. Essa "cultura fronteiriça", perpassada por elementos transnacionais, une os dois lados do Rio Uruguai em intensa troca cultural. O samba, incluído entre os bens culturais em trânsito, integra, dessa forma, não apenas diferentes classes sociais, como tradicionalmente sociólogos e antropólogos concebem, mas também povos de diferentes nacionalidades. Vários desfilantes das agremiações carnavalescas de Uruguaiana são argentinos, participando, por exemplo, das baterias. Muitas fantasias importantes também são confeccionadas no país vizinho.

Em Paso de los Libres, na outra margem do Rio Uruguai, as escolas de samba também são a atração principal dos festejos carnavalescos. A propaganda turística da cidade destaca o "carnaval no estilo brasileiro", que constitui a particularidade da região em relação às demais cidades da província de Corrientes. Na cidade argentina já existe, aliás, um sambódromo construído para servir de palco às agremiações carnavales- 
cas, ao contrário de Uruguaiana, que realiza seu espetáculo em passarela montada temporariamente na Avenida Presidente Vargas, no Centro da cidade. Se os desfiles do lado brasileiro da fronteira acontecem após a data oficial de carnaval, em Paso de los Libres eles ocorrem em quatro finais de semana seguidos, mantendo a atenção da população e atraindo turistas, interessados na "maior festa popular da fronteira", durante todo o período de atividades.

Segundo Roberta Brandalise, que realizou estudo sobre o consumo televisivo na região fronteiriça entre Brasil e Argentina, o carnaval tornou-se elemento identificador entre uruguaianenses e librenhos. Nas entrevistas realizadas pela autora, ele aparece como elemento da cultura nacional brasileira que se transportou, através dos meios de comunicação, para a localidade de Uruguaiana. Através do cotidiano fronteiriço que a cidade argentina partilha com Uruguaiana e pelos meios de comunicação brasileiros, aos quais os argentinos da fronteira têm amplo acesso, o carnaval se teria tornado tradição cultural de Paso de los Libres. Os comentários sobre o carnaval, acrescenta Brandalise (2010, p. 6), demonstram que os argentinos identificam o uruguaianense mais com a noção de cultura nacional brasileira do que com a cultura regional comum aos fronteiros.

Assim, na realidade cultural da fronteira, os elementos culturais nacionais, regionais e transnacionais se entrecruzam em complexa relação que, em vez dos sentidos de homogeneização e resistência, apresentam aspectos sui generis que ignoram as classificações dicotômicas mais usuais, como "brasileiro" x "gaúcho" ou "brasileiro" x "argentino". No caso de Uruguaiana, o fato de estar localizada na fronteira, ao invés de provocar o distanciamento dos elementos nacionais, no caso oriundos da antiga capital federal, o Rio de Janeiro, permitiu justamente o contrário. É exatamente por estar na fronteira que se tornou necessário reforçar militarmente a região, trazendo soldados e, consequentemente, suas práticas culturais. Dessa forma, paradoxalmente, o fato de ser uma cidade de fronteira reforça a presença dos elementos culturais centrais, o que, como vimos, aproxima Uruguaiana do Rio de Janeiro e a distancia das cidades que estão a seu redor e da capital do próprio estado, Porto Alegre. No jogo das diversas identidades que perpassam o desfile carnavalesco fora de época em Uruguaiana, elementos nacionais brasileiros, regionais do Rio Grande do Sul e argentinos se integram e unem as duas margens do Rio Uruguai, um dia separadas pelas rivalidades entre os homens e suas nações. É a magia do carnaval vencendo a política e as diferenças históricas. É o samba da fronteira pedindo passagem.

\section{REFERÊNCIAS BIBLIOGRÁFICAS}

ALVES, Francisco. Samba: uma das heranças dos fuzileiros navais. Revista LIESU 2009. Uruguaiana, 2009, p. 10-12.

ANDERSON, Benedict. Comunidades imaginadas: reflexões sobre a origem e a difusão do nacionalismo. São Paulo: Companhia das Letras, 2008.

BRANDALISE, Roberta. O consumo da televisão brasileira na fronteira Brasil-Argentina. Trabalho apresentado na XIV Colóquio Internacional sobre a Escola Latino-Americana de Comunicação - Celacom. São Paulo, 2010. 
FERNANDES, Nelson da Nóbrega. Escolas de samba: sujeitos celebrantes e objetos celebrados. Rio de Janeiro: Arquivo Geral da Cidade do Rio de Janeiro, 2001.

PAVÃo, Fábio Oliveira. A dança da identidade: os usos e significados do samba no mundo globalizado. Tese de doutorado apresentada ao Programa de Pós-graduação em Antropologia da Universidade Federal Fluminense. Niterói, 2010.

SIMSON, Olga Rodrigues de Moraes Von. Carnaval em branco e negro: carnaval popular paulistano: 1914-1988. Campinas: Editora Unicamp, 2007.

VIANNA, Hermano. O mistério do samba. Rio de Janeiro: Zahar, 2007.

YÚDICE, George. A conveniência da cultura: usos da cultura na era global. Belo Horizonte: Editora UFMG, 2006.

Fábio Pavão é mestre e doutor em Antropologia pelo PPGA/UFF, licenciado e bacharel em Ciências Sociais (UERJ), especialista em sociologia urbana (UERJ). 